\title{
Evaluating the Applicability of Fracture Criteria to Predict the Crack Evolution Path of Dolomite Based on SCB Experiments and FEM
}

\author{
Cunbao Li, ${ }^{1,2}$ Lingzhi Xie, ${ }^{1,2}$ Li Ren, ${ }^{1,2}$ Heping Xie, ${ }^{1,2}$ and Jun Wang ${ }^{1,2}$ \\ ${ }^{1}$ Key Laboratory of Energy Engineering Safety and Disaster Mechanics of Ministry of Education, Sichuan University, \\ Chengdu 610065, China \\ ${ }^{2}$ School of Architecture and Environment, Sichuan University, Chengdu 610065, China
}

Correspondence should be addressed to Lingzhi Xie; xielingzhi@scu.edu.cn

Received 2 October 2013; Revised 17 November 2013; Accepted 18 November 2013

Academic Editor: Goangseup Zi

Copyright (C) 2013 Cunbao Li et al. This is an open access article distributed under the Creative Commons Attribution License, which permits unrestricted use, distribution, and reproduction in any medium, provided the original work is properly cited.

\begin{abstract}
Mixed mode fracture tests are conducted under various initial loading combinations of mode I and mode II (from pure mode I to pure mode II) on semicircular bend (SCB) specimens of dolomite rock. Damage zones are observed behind the fracture surfaces of the broken samples. Scanning electron microscope images of the fracture surfaces are used to study the failure manner. Using the conventional remesh method based on the finite element method (FEM), several widely accepted fracture criteria are employed to theoretically predict the fracture paths. These criteria include the maximum tangential stress criterion, minimum strain energy density criterion, maximum energy release rate criterion, maximum dilatational strain energy density criterion, and the distortional strain energy density criterion. The applicability of the five fracture criteria is examined. The results show that none of the criteria are successful in predicting the crack trajectories of the predominately mode II cracks; the differences among the predicted results of the crack growth paths are negligible for each crack inclined angle. The effect of Poisson's ratio on the fracture criteria is also investigated and the results show that the predicted crack trajectories are not sensitive to Poisson's ratio.
\end{abstract}

\section{Introduction}

Extensive development in rock fracture mechanics research has covered many diverse areas including blasting, hydraulic fracturing and in situ stress determination, mechanical fragmentation, rock slope analysis, earthquake mechanics, earthquake prediction, plate tectonics, magmatic intrusions, hot dry rock geothermal energy extraction, fluid transport properties of fracturing rock masses, propagating oceanic rifts, crevasse penetration, and other glaciological problems [1]. As a result of complicated geological processes, numerous flaws, cracks, and faults exist in rock masses. Fracture mechanics is a useful technique for investigating the initiation and propagation of an individual crack or cracks in geological materials. Due to the complexity of in situ stresses, most fractures in these applications occur under a combination of opening and sliding deformation (I/II mixed mode). Under mixed mode loading, a fracture usually propagates along a curvilinear path
[2]. However, it is quite difficult to predict the curvilinear fracture path theoretically because the crack growth direction has to be determined by the present mixed-mode loading condition which corresponds to a specified position on the curvilinear path. Further investigations into fracture initiation angle and fracture propagation path under mixed-mode loading will improve the understanding of mixed mode fracture behavior.

Many researches have been conducted to describe crack initiation and crack propagation under mixed-mode loading. For example, Jia et al. [3] conducted a series of mixedmode fracture experiments using center cracked circular disc (CCCD) specimens to observe the fracture path of concrete under mixed mode I/II loading; Xeidakis et al. [4] investigated the trajectory of crack growth for marble using antisymmetric three-point bend specimens under different mixed mode loading conditions; Bobet and Einstein [5] studied the fracture initiation, propagation, and, ultimately, 
coalescence (which plays an important role in the behavior of brittle materials) by loading prefractured specimens of gypsum, used as the rock model material, in uniaxial and biaxial compression; Chen et al. [6] conducted a set of fracture experiments on anisotropic shale by using CCCD specimens under different mixed mode loading conditions for studying the fracture initiation path and also employed the numerical technique of boundary element method to simulate the observed fracture paths. Vásárhelyi and Bobet [7] investigated the crack initiation stress, direction, and propagation of newly generated cracks for both open and closed fractures; Wong et al. [8] numerically investigated the crack initiation, propagation, and coalescence of rock specimens containing preexisting crack-like flaws under compression by using Rock Failure Process Analysis $\left(\mathrm{RFPA}^{2 \mathrm{D}}\right)$; Al-shayea [9] studied the crack initiation angle and subsequent crack propagation path experimentally for notched Brazilian disk specimens of limestone; Liu et al. [10] used a numerical method for modeling the mixed mode fracture process of heterogeneous rocks using different test samples including CCCD specimens. More recently, Aliha et al. [11] investigated the mixed mode I/II fracture initiation angle and the crack growth trajectory of soft rock (Guiting Limestone) by using both CCCD and edge cracked SCB specimens of various sizes.

In order to theoretically estimate the crack initiation angle, several widely accepted fracture criteria have been proposed, for example, the maximum tangential stress criterion ( $\sigma_{\theta}$-criterion) [12], minimum strain energy density criterion ( $S_{\min }$-criterion) [13], maximum energy release rate criterion ( $G_{\max }$-criterion) [14-18], maximum dilatational strain energy density criterion (NT-criterion) [19], and distortional strain energy density criterion ( $Y$-criterion) [20]. From a material mechanics view, it is reasonable to suggest that mixed mode brittle fracture occurs on reaching a certain level of critical energy, tensile stress, tensile strain, shear stress, shear strain, or another physical variable near the crack tip. However, it seems that none of these variables can predict the fracture strengths of predominately mode II fractures accurately because each criterion will predict a corresponding invariant fracture toughness ratio $K_{\mathrm{II}} / K_{\mathrm{Ic}}$ [2] which cannot be applied to a wide range of engineering materials. In fracture mechanics, it is also important to predict where the crack will go, that is, the initiation angle and the growth path of the crack. Therefore, the applicability of these fracture criteria on the crack growth direction and crack evolution path should be discussed.

In this study, a series of mixed-mode fracture tests are conducted on dolomite rock using SCB specimens. Additionally, scanning electron microscope (SEM) images are used to study the failure manner. Moreover, using the conventional remesh method based on the FEM, the crack growth trajectories for various mixed mode loading conditions (from pure mode I to mode II) are theoretically (by the $\sigma_{\theta}$-criterion, $S_{\min }{ }^{-}$ criterion, $G_{\max }$-criterion, $N T$-criterion, and $Y$-criterion) and numerically predicted. A detailed investigation on the applicability of the five fracture criteria to the prediction of crack evolution paths under mixed mode loading conditions has been presented. Finally, the effect of Poisson's ratio on the fracture criteria is also investigated.

\section{Crack Propagation Criteria}

Most theoretical fracture criteria consider that when an appropriate characteristic quantity like stress, strain, and energy density energy release rate, in front of the crack tip reaches its critical value which is deemed to a material constant, then the crack begins propagating. For plane problem, the singular stresses around a crack tip in polar coordinate can be expressed as

$$
\begin{aligned}
& \sigma_{r r}=\frac{1}{\sqrt{2 \pi r}}\left[\frac{K_{\mathrm{I}}}{2} \cos \frac{\theta}{2}(3-\cos \theta)-\frac{K_{\mathrm{II}}}{2} \sin \frac{\theta}{2}(1-3 \cos \theta)\right], \\
& \sigma_{\theta \theta}=\frac{1}{\sqrt{2 \pi r}}\left[\frac{K_{\mathrm{I}}}{2} \cos \frac{\theta}{2}(1+\cos \theta)-\frac{3 K_{\mathrm{II}}}{2} \sin \frac{\theta}{2}(1+\cos \theta)\right], \\
& \sigma_{r \theta}=\frac{1}{\sqrt{2 \pi r}}\left[\frac{K_{\mathrm{I}}}{2} \sin \frac{\theta}{2}(1+\cos \theta)-\frac{K_{\mathrm{II}}}{2} \cos \frac{\theta}{2}(1-3 \cos \theta)\right],
\end{aligned}
$$

where $r$ and $\theta$ are the polar coordinates with the origin at the crack tip and $K_{\mathrm{I}}$ and $K_{\mathrm{II}}$ are mode I and mode II stress intensity factors, respectively. And the stress field in Cartesian coordinates is defined as

$$
\begin{gathered}
\sigma_{x x}=\frac{1}{\sqrt{2 \pi r}}\left[K_{\mathrm{I}} \cos \frac{\theta}{2}\left(1-\sin \frac{\theta}{2} \sin \frac{3 \theta}{2}\right)\right. \\
\left.-K_{\mathrm{II}} \sin \frac{\theta}{2}\left(2+\cos \frac{\theta}{2} \cos \frac{3 \theta}{2}\right)\right], \\
\sigma_{y y}=\frac{1}{\sqrt{2 \pi r}}\left[K_{\mathrm{I}} \cos \frac{\theta}{2}\left(1+\sin \frac{\theta}{2} \sin \frac{3 \theta}{2}\right)\right. \\
\left.+K_{\mathrm{II}} \sin \frac{\theta}{2} \cos \frac{\theta}{2} \cos \frac{3 \theta}{2}\right], \\
\sigma_{x y}=\frac{1}{\sqrt{2 \pi r}}\left[K_{\mathrm{I}} \cos \frac{\theta}{2} \sin \frac{\theta}{2} \sin \frac{3 \theta}{2}\right. \\
\left.+K_{\mathrm{II}} \cos \frac{\theta}{2}\left(1-\sin \frac{\theta}{2} \sin \frac{3 \theta}{2}\right)\right], \\
\sigma_{z z}=0, \text { for plane stress, } \\
\sigma_{z z}=\nu\left(\sigma_{x x}+\sigma_{y y}\right), \text { for plane strain, }
\end{gathered}
$$

where $v$ is Poisson's ratio.

2.1. $\sigma_{\theta}$-Criterion. Erdogan and Sih [12] propose the maximum tangential stress criterion, which considers that a crack would grow in the direction in which the $\sigma_{\theta \theta}$ is the maximum; the direction should meet the following conditions:

$$
\frac{\partial \sigma_{\theta \theta}}{\partial \theta}=0, \quad \frac{\partial^{2} \sigma_{\theta \theta}}{\partial \theta^{2}}<0 .
$$

2.2. $S_{\min }$-Criterion. Sih [13] formulates the specific stain energy density factor $S$ at the radius $r_{0}$ in term of the energy as follows:

$$
S=a_{11} K_{\mathrm{I}}^{2}+2 a_{12} K_{\mathrm{I}} K_{\mathrm{II}}+a_{22} K_{\mathrm{II}}^{2}
$$


where

$$
\begin{gathered}
a_{11}=\frac{1}{16 \pi \mu}(1+\cos \theta)(\kappa-\cos \theta), \\
a_{12}=\frac{1}{16 \pi \mu} \sin \theta(2 \cos \theta-\kappa+1), \\
a_{22}=\frac{1}{16 \pi \mu}[(\kappa+1)(1-\cos \theta)+(1+\cos \theta)(3 \cos \theta-1)],
\end{gathered}
$$

where $\mu$ is the shear modulus, $\kappa=3-4 \nu$ for the plane strain problem, and $\kappa=(3-4 v) /(1+\nu)$ for the plane stress problem. The $S_{\min }$-criterion postulates that the crack initiates in the direction of minimum strain energy density along a constant radius around the crack tip when $S$ reaches a critical value; that is,

$$
\frac{\partial S}{\partial \theta}=0, \quad \frac{\partial^{2} S}{\partial \theta^{2}}>0
$$

2.3. $G_{\max }$-Criterion. Several forms [15-18] of $G_{\max }$-criterion have been formulated and only the expressions presented by Hussain et al. [15] will be reviewed here. The energy release rate is given as

$$
\begin{aligned}
G= & \frac{4}{E}\left(\frac{1}{3+\cos ^{2} \theta}\right)^{2}\left(\frac{\pi+\theta}{\pi-\theta}\right)^{-\theta / \pi} \\
& \times\left[\left(1+3 \cos ^{2} \theta\right) K_{\mathrm{I}}^{2}-4 \sin (2 \theta) K_{\mathrm{I}} K_{\mathrm{II}}+\left(9-5 \cos ^{2} \theta\right) K_{\mathrm{II}}^{2}\right],
\end{aligned}
$$

where $E$ is Young's modulus. According to the assumptions made by Palaniswamy and Knauss [14], the direction of crack propagation is the orientation in which the maximum rate of elastic energy release rate once exceeds a critical value; that is,

$$
\frac{\partial G}{\partial \theta}=0, \quad \frac{\partial^{2} G}{\partial \theta^{2}}<0
$$

2.4. NT-Criterion. In NT-criterion [19] the total strain energy density $N$ (equivalent to $S$ in (4)) is split into the distortional stain energy density $N_{d}$ and dilatational stain energy density $N_{v}$; that is,

$$
N=N_{d}+N_{v}
$$

where

$$
\begin{aligned}
N_{d}= & \frac{1}{6 \mu} \\
& \times\left(\sigma_{x x}^{2}+\sigma_{y y}^{2}+\sigma_{z z}^{2}-\sigma_{x x} \sigma_{y y}-\sigma_{y y} \sigma_{z z}-\sigma_{z z} \sigma_{x x}+3 \sigma_{x y}^{2}\right), \\
& N_{v}=\frac{1}{18 K}\left(\sigma_{x x}+\sigma_{y y}+\sigma_{z z}\right)^{2}, \quad K=\frac{E}{3(1-2 \nu)} .
\end{aligned}
$$

The elastic-plastic boundary then can be obtained by employing a suitable yield condition, and in NT-criterion, the Von Mises yield function is adopted. Then, one can have

$$
N_{d, 0}=\frac{\sigma_{y}^{2}}{6 \mu}
$$

where $\sigma_{y}$ is the critical material yield strength. NT-criterion postulates that a crack propagates in the direction of maximum dilatational strain energy $N_{v, \max }$ along the contour of constant distortional strain energy $N_{d, 0}$ when the distance from crack tip to the elastic-plastic boundary $r_{p}$ in the growth direction reached a critical value $r_{p c r}$; that is,

$$
\frac{\partial N_{v \mid r_{p}}}{\partial \theta}=0, \quad \frac{\partial^{2} N_{v \mid r_{p}}}{\partial \theta^{2}}<0,
$$

where $r_{p c r}=(1-2 v)^{2} K_{I c}^{2} /\left(2 \pi \sigma_{y}^{2}\right)$ for plane strain and $r_{p c r}=$ $K_{I c}^{2} /\left(2 \pi \sigma_{y}^{2}\right)$ for plane stress case.

2.5. Y-Criterion. $Y$-criterion [20] also divides the total energy density into two components, the dilatational stain energy density $Y_{v}$ and the distortional strain energy density $Y_{d}$, as

$$
Y_{d}=N_{d}, \quad Y_{v}=N_{v} .
$$

$Y$-criterion presumes that a crack growth occurs in the direction of minimum distortional strain energy density along the constant core region boundary $r_{0}$ when the minimum distortional strain energy density $Y_{d, \theta_{0}}$ reached a critical value $Y_{d, 0}$, and it can expressed as

$$
\frac{\partial Y_{d \mid r_{0}}}{\partial \theta}=0, \quad \frac{\partial^{2} Y_{d \mid r_{0}}}{\partial \theta^{2}}>0 .
$$

\section{Mixed Mode Fracture Tests on Dolomite Rock}

3.1. Rock Properties. The experimental material, dolomite rock, was taken from a quarry in Fangshan County, Beijing. Visual inspections indicated that the rock was isotropic, homogenous, and white in color. Its structure was continuous and very tight. The X-ray diffraction (XRD) analysis (Figure 1) showed that the rock was composed of dolomite $\left(\mathrm{CaMg}\left(\mathrm{CO}_{3}\right)_{2}\right)$ and quartz $\left(\mathrm{SiO}_{2}\right)$. No pores or microcracks were visible using SEM with $\times 50$ magnification (Figure 2), therefore, the porosity of this rock can be neglected. SEM images also identified the material as a microcrystallinetextured, fine grained rock. Its dry density was about $2.59 \mathrm{~g} / \mathrm{mm}^{3}$. In order to get the mechanical properties of dolomite rock, 4 groups of uniaxial compression tests and 4 groups of Brazilian tests were conducted. The mechanical properties of the rock included a uniaxial unconfined compressive strength of $135 \mathrm{MPa}$, a tensile strength of $3.0 \mathrm{MPa}$, Young's modulus of elasticity of $50 \mathrm{GPa}$, and Poisson's ratio of 0.25 . 


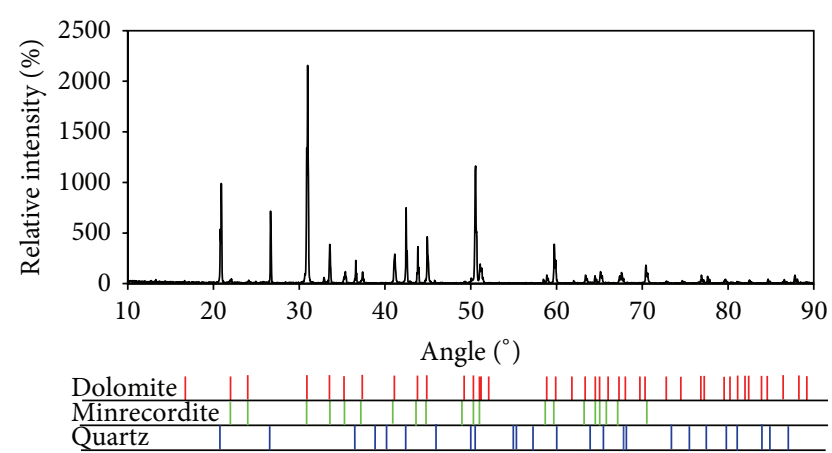

FIGURE 1: XRD results for dolomite rock.

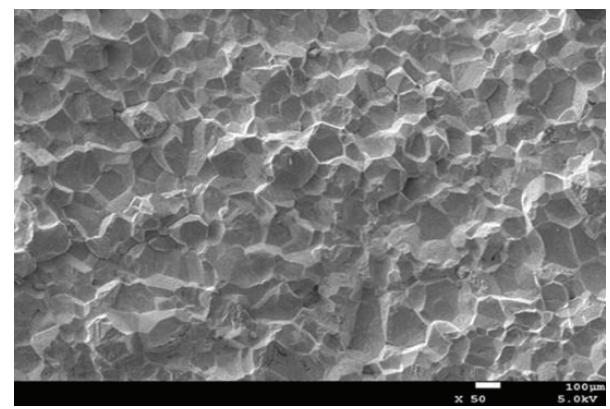

FIGURE 2: SEM image for dolomite rock with $\times 50$ magnifications.

3.2. Sample Preparation. The SCB specimens [21] were selected for mixed mode fracture tests on dolomite rock. Figure 3 shows the geometry of the SCB specimen and the loading setup of the experiments. SCB specimen was a half disc of radius $R$ and thickness $t$. The edge crack was of length $a$ and angle $\alpha$ relative to the loading direction. The specimen was loaded by a vertical load $P$ under three-point bending and the distance between the bottom supports was $2 s$. When $\alpha$ was zero, the specimen was subjected to pure mode I (opening mode) independent of $a / R$ and $s / R[22]$. By increasing the angle $\alpha$, the contribution of mode II (or sliding mode) to the crack deformation increased. Pure mode II took place at a specific angle $\alpha$ depending on $a / R$ and $s / R$ [22].

To avoid any possible boundary effects, the specimens were taken from the center of the rocks. The SCB specimens had a radius of $25 \mathrm{~mm}$ and were $15 \mathrm{~mm}$ in thickness. Values of $a / R=0.4$ and $s / R=0.4$ were selected for all the specimens. The cracks were created using a $0.2 \mathrm{~mm}$ thick diamond impregnated wire saw and the crack length $a$ was $10 \mathrm{~mm}$. According to [22] and numerical analysis, for the selected specimen configuration and loading condition, at an inclination angle of $34.8^{\circ}$ the crack was pure mode II crack. Therefore, the crack inclination angles of $\alpha=0^{\circ}$ (pure mode I), $10^{\circ}, 20^{\circ}, 30^{\circ}, 34.8^{\circ}$ (pure mode II), and $40^{\circ}$ (compressionshear mode) were selected. For each crack angle, four samples were prepared.

3.3. Fracture Tests. Each SCB specimen was located inside a three-point bending fixture (Figure 3 ) and then loaded by

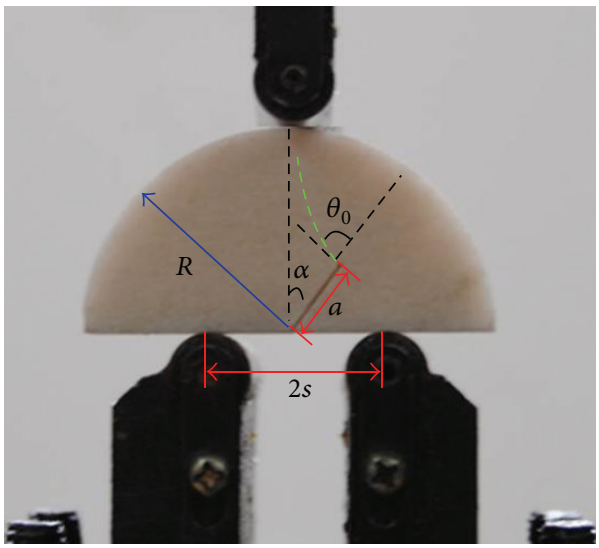

FIgURE 3: Geometrical characteristics of specimens and loading setup.

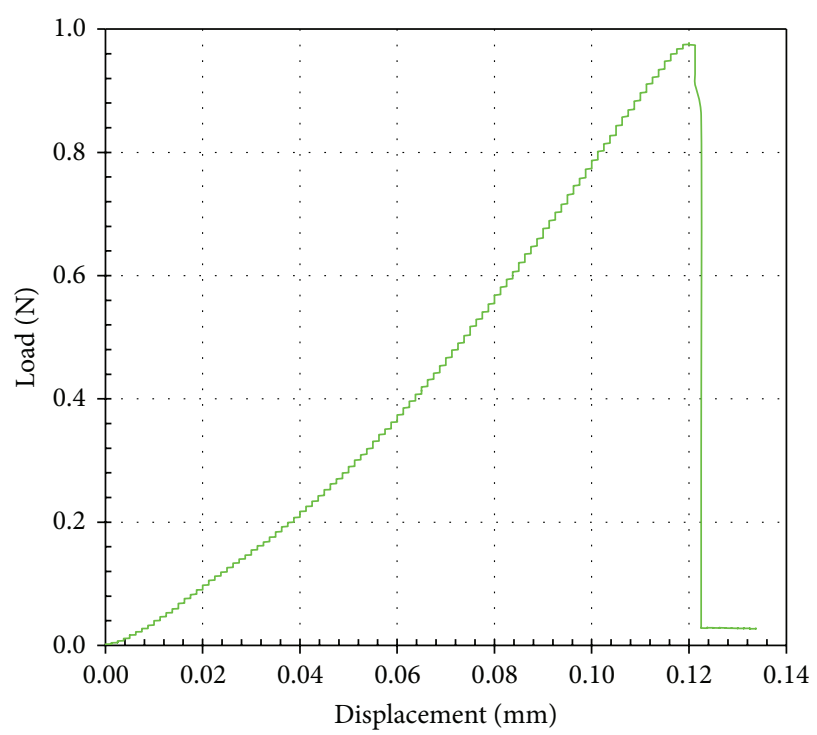

FIgURE 4: Typical plot of the applied load against the load-point displacement.

a test machine with a capacity of $10 \mathrm{kN}$. The loading rate was set to $0.1 \mathrm{~mm} / \mathrm{min}$ for all the experiments. Figure 4 represents a typical plot of the applied load against load-point displacement. It can be seen that after a nonlinear stage the load-displacement curve gives a linear relationship up to the maximum load. The dolomite specimens, including the crack, remain stable without any visible changes during the loading process until the load reaches a critical value. At that point the load-displacement curve drops suddenly, which is the characteristic of brittle fracture; the original crack propagates rapidly toward to the point where the load is applied. When the crack reaches the edge of the specimen, the specimen breaks into two pieces (Figure 5). The fracture surfaces can reveal some useful information about the failure mechanism. Therefore, SEM was used to conduct a microscale investigation on the typical fracture surfaces. 
TABLE 1: Failure loads $P_{c r}$ obtained from mixed mode fracture tests.

\begin{tabular}{|c|c|c|}
\hline Specimen code & $\begin{array}{l}\text { Crack inclined } \\
\text { angle } \alpha\left(^{\circ}\right)\end{array}$ & $\begin{array}{c}\text { Failure load } \\
(N)\end{array}$ \\
\hline D-1 (pure mode I) & 0 & 832 \\
\hline D-2 (pure mode I) & 0 & 857 \\
\hline D-3 (pure mode I) & 0 & 846 \\
\hline D-4 (pure mode I) & 0 & 836 \\
\hline D-5 & 10 & 925 \\
\hline D-6 & 10 & 910 \\
\hline D-7 & 10 & 892 \\
\hline D-8 & 10 & 945 \\
\hline D-9 & 20 & 960 \\
\hline D-10 & 20 & 810 \\
\hline D-11 & 20 & 929 \\
\hline $\mathrm{D}-12$ & 20 & 901 \\
\hline $\mathrm{D}-13$ & 30 & 1002 \\
\hline D-14 & 30 & 936 \\
\hline D-15 & 30 & 997 \\
\hline D-16 & 30 & 993 \\
\hline D-17 (pure mode II) & 34.8 & 1001 \\
\hline D-18 (pure mode II) & 34.8 & 1035 \\
\hline D-19 (pure mode II) & 34.8 & 1210 \\
\hline D-20 (pure mode II) & 34.8 & 890 \\
\hline $\mathrm{D}-21$ & 40 & 956 \\
\hline $\mathrm{D}-22$ & 40 & 1256 \\
\hline D-23 & 40 & 1254 \\
\hline D-24 & 40 & 1042 \\
\hline
\end{tabular}

3.4. Test Results and Analysis. The failure loads $P_{c r}$ obtained from the mixed mode fracture tests are listed in Table 1 . The average values of $P_{c r}$ for $\alpha=0^{\circ}, 10^{\circ}, 20^{\circ}, 30^{\circ}, 34.8^{\circ}$, and $40^{\circ}$ are $840 \mathrm{~N}, 918 \mathrm{~N}, 930 \mathrm{~N}, 982 \mathrm{~N}, 1034 \mathrm{~N}$, and $1127 \mathrm{~N}$, respectively. The failure load increases gradually as the proportion of mode II deformation increases.

Crack initiation includes two components: the crack initiation angle and the crack initiation point. According to linear elastic fracture mechanics (LEFM), the crack initiation point is usually expected to be the crack tip of the original crack. However, for specimens with $\alpha=30^{\circ}$ and $34.8^{\circ}$ (pure mode II), the crack initiation point is not from the crack tip, as shown in Figure 5. Generally, only when the crack inclination angle $\alpha$ is very large, usually bigger than the values of pure mode II or when the crack tip is obtuse seriously, the crack initiation point may not originate from the crack tip. However, the two cases in the tests do not fall into either of these two categories. In order to better explain such phenomenon, the fracture surface near the crack tip has been observed with SEM. It is found that the mineral grain near the crack tip is much larger than that in the surrounding area (Figure 6), which may lead to this unexpected failure behavior. The other reason may be that the specimen contains quartz, which possesses a much higher strength than dolomite. It is difficult to evaluate the influence of the size of the particles

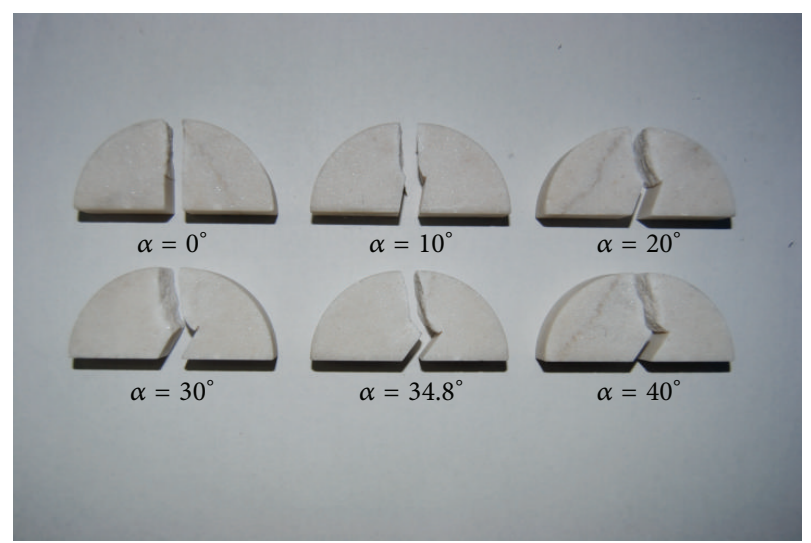

Figure 5: SCB specimens after failure.

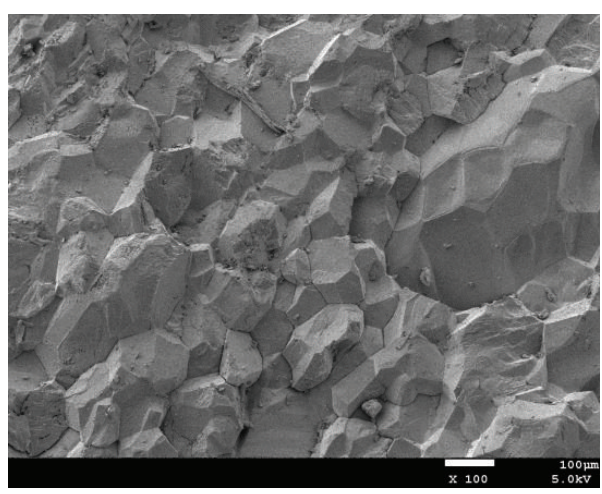

FIGURE 6: Size of particles around the crack tip $\left(\alpha=30^{\circ}\right)$.

and the mineral composition on the crack initiation, either qualitatively or quantitatively.

Dolomite is a brittle rock with a relatively low hardness. After the failure of specimens, an obvious damaged zone can be found for each specimen, as illustrated in Figure 7. The damage zone is narrow relative to the specimen. The color of the damaged zone is different from the surrounding area; its color is much whiter obviously. Regardless of the position of crack tip, a high stress zone must exist around the crack tip and lead to damage. Fonseka et al. [23] has confirmed this view using the technology of SEM and acoustic emission (AE). But this is a macroscopic experiment that may demonstrate directly that the emergence of a macroscopic crack is the result of damage that develops from microcracks and microvoids.

SEM image was used to examine the failure manner to better understand the fracture mechanism and the evolution of the damage in dolomite rock. The fracture faces near the original crack tip for the cases of $\alpha=0^{\circ}, 10^{\circ}, 20^{\circ}, 30^{\circ}, 34.8^{\circ}$, and $40^{\circ}$ were observed by SEM; the fracture faces produced by the Brazilian test were also studied for comparison. Figure 8 shows SEM images of crack surface of the dolomite SCB specimens and Brazilian test with $\times 100$ magnification.

In the case of $\alpha=0^{\circ}$ (Figure 8(a)), the cracked surface is coarse which was mainly caused by intergranular failure. Compared with the fracture surface of the broken sample 


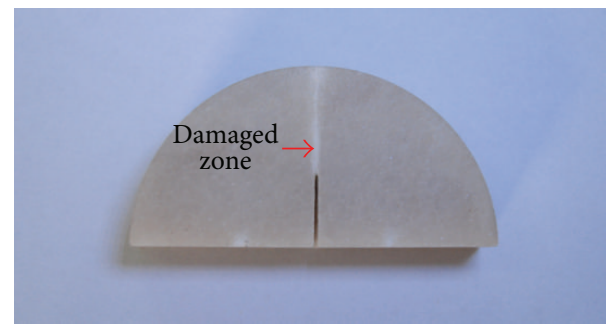

FIGURE 7: Visible damaged zone of a specimen.

from a Brazilian test (Figure $8(\mathrm{~g})$ ), the two faces are very similar, indicating that the specimen is destroyed by splitting and stretching. The SEM image for $\alpha=10^{\circ}$ (Figure 8(b)) shows that the cracked surface is also produced primarily by splitting, tensile stress is the main factor, and only few of the crystalline particles are sheared off. There is no evidence of crushing or friction. The micrograph for the case of $\alpha=$ $20^{\circ}$ illustrates that the fractured surface is similar to that of $\alpha=10^{\circ}$ image. The notable difference is the increment of transgranular damage, revealing that the impact of shear stress is increasing, although it is still small relative to the effect of splitting. There is still no evidence of crushing in the specimen of $\alpha=20^{\circ}$. In the SEM image for $\alpha=30^{\circ}$ the transgranular damage becomes more apparent; the fractured surface is produced by a combination of splitting and sliding shear. When the angles are $\alpha=34.8^{\circ}$, and $40^{\circ}$, the SEM images show obvious crushing between the boundary of the crystals. For $\alpha=34.8^{\circ}$, the failure is due to shear stress that is consistent with LEFM. For the specimens of $\alpha=40^{\circ}$, crushing is more serious. The analysis indicates that when the angle increases from pure mode I to pure mode II, the effect of the shear stress grows, but there is no crushing or abrasion on the cracked surface, which is different from the results proposed in previous studies [9]. Moreover, when the angle reaches pure mode II or continues to increase (compression-shear mode), the signs of crushing become apparent, with many rock fragments observed on the fractured surface.

\section{Numerical Analysis and Comparison}

Based on (1)-(14), the crack initiation direction and growth path can be derived. Equations (1)-(14) are functions of the stress intensity factors and various material constants. By using the conventional remesh method based on FEM, (1)(14) were employed to theoretically predict the fracture paths. No dynamic effects were considered in the crack propagation process. The finite element code ABAQUS and the mathematical software MATLAB were combined to evaluate the direction of crack growth. Stress intensity factors calculated by ABAQUS would output to a specified file, and fracture criterion was written as a program by MATLAB. The program would read stress intensity factors from the specified file and calculate the angle in which the crack would propagate. In each step, the simulation model was remodeled with a small crack extension of $0.5-1 \mathrm{~mm}$. In the initial steps, the extension was relatively small. As the crack tip gradually approached the loading point, the crack extension of each step became larger. Generally, simulating each model required at least 21 steps. The following procedure gave more details for predicting the crack evolution path using the five fracture criteria:

(1) calculating $K_{\mathrm{I}}$ and $K_{\mathrm{II}}$ for the existing crack,

(2) using each criterion to evaluate the corresponding crack growth direction,

(3) remodeling the crack with a small extension along the direction which was calculated in step 2,

(4) repeating steps 1-3 for the new crack growth.

The loading conditions were considered similar to those of the fracture tests; for $\alpha=0^{\circ}, 10^{\circ}, 20^{\circ}, 30^{\circ}, 34.8^{\circ}$, and $40^{\circ}$, the loads were $840 \mathrm{~N}, 918 \mathrm{~N}, 930 \mathrm{~N}, 982 \mathrm{~N}, 1034 \mathrm{~N}$, and $1127 \mathrm{~N}$, respectively. ABAQUS provides a domain integral method to compute the stress intensity factors directly for a crack under mixed-mode loading. To produce the square root singular of the stress/strain field, the singular elements were considered in the first ring of elements surrounding the crack tip. In order to ensure a smooth curve which was the boundary of domain integral used to calculate stress intensity factors, 8 rings of quadratic quadrilateral elements surrounding the singular elements were meshed by the meshing technique of sweep. Other regions of the numerical model were meshed by the meshing methods of sweep or free, and the element type was also quadratic quadrilateral elements. A total of about 5000 eight-node plane strain elements (CPE8) were used for each model. Figure 9 represents a typical finite element mesh used for numerical analysis. The alterations of $K_{\mathrm{I}}$ and $K_{\mathrm{II}}$ with the mesh density are shown in Figure 10. It is observed that the values of $K_{\mathrm{I}}$ and $K_{\mathrm{II}}$ are not sensitive to mesh density. The mesh density adopted in this research is reasonable. Using the method described above, the crack initiation angle and crack propagation path for different crack inclined angles were analyzed. The experimental and numerical results were compared to evaluate the applicability of the fracture criteria to predict the crack evolution path of dolomite rock.

The impact of Poisson's ratio on the crack initial direction and crack propagation path was also considered. Poisson's ratio of the experimental dolomite SCB specimens was 0.25 . Thus numerical models with Poisson's ratio of 0.1, 0.25, and 0.4 were simulated.

4.1. Crack Initiation Angle. The crack initiation angle $\theta_{0}$ is the direction in which the crack propagates from the original crack (Figure 3). For different $\alpha$, the value of $\theta_{0}$ is calculated by each fracture criteria introduced in Section 2. Table 2 summarizes the crack initiation angle from simulated results.

Generally, the point possesses maximum stress, and maximum energy is at different locations and in a different direction, so the crack initiation angle predicted by different fracture criteria should be different. When mode I deformation is dominant $\left(\alpha<10^{\circ}\right)$, the difference in crack initiation angle is very small. The maximum difference between the predicted angles is $3.8^{\circ}$ (between the $S_{\min }$-criterion and $G_{\max }$-criterion), and there is little difference between the $\sigma_{\theta}$-criterion and 


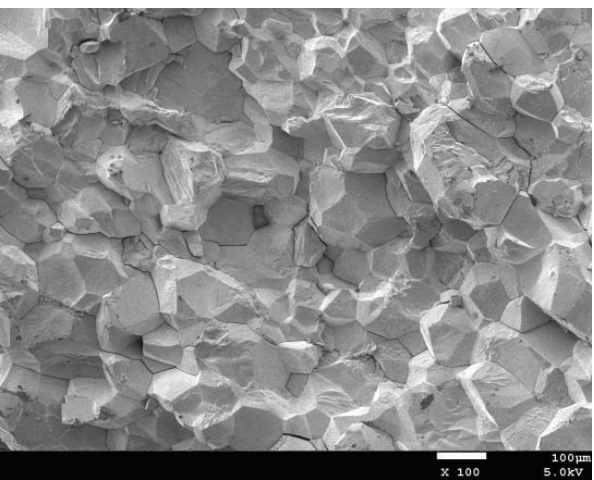

(a) $\alpha=0^{\circ}$

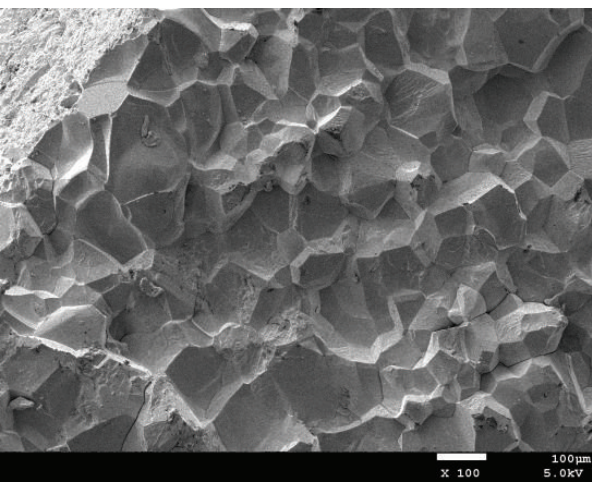

(c) $\alpha=20^{\circ}$

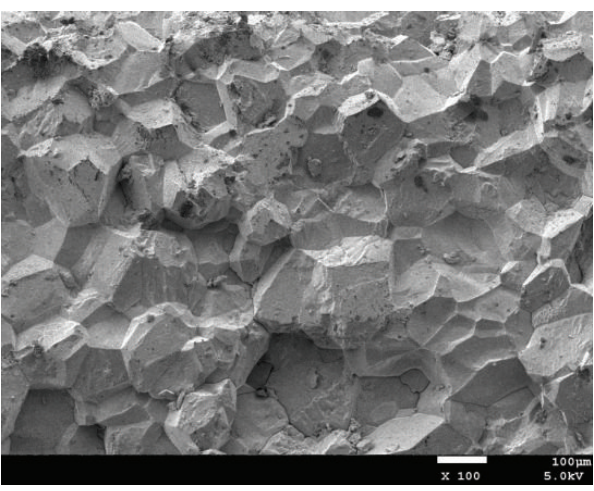

(e) $\alpha=34.8^{\circ}$

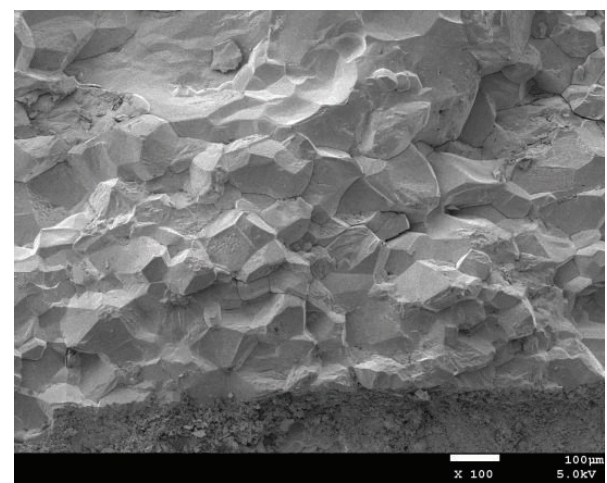

(b) $\alpha=10^{\circ}$

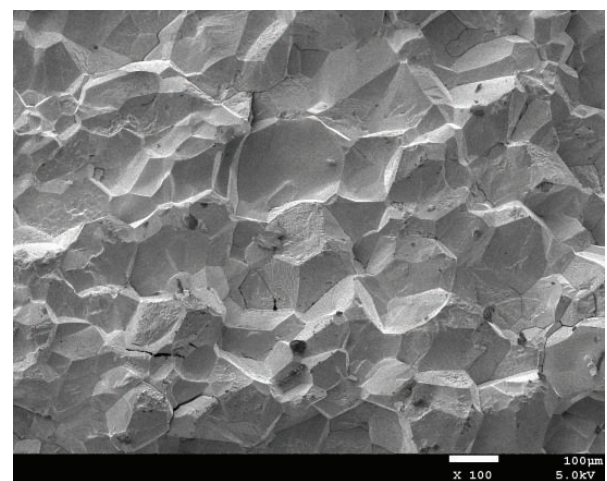

(d) $\alpha=30^{\circ}$

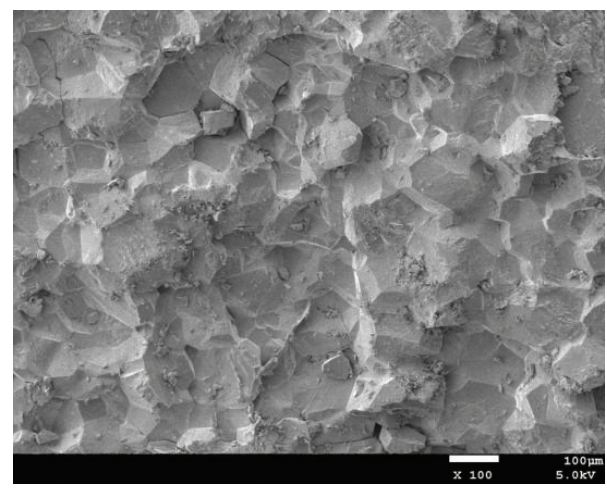

(f) $\alpha=40^{\circ}$

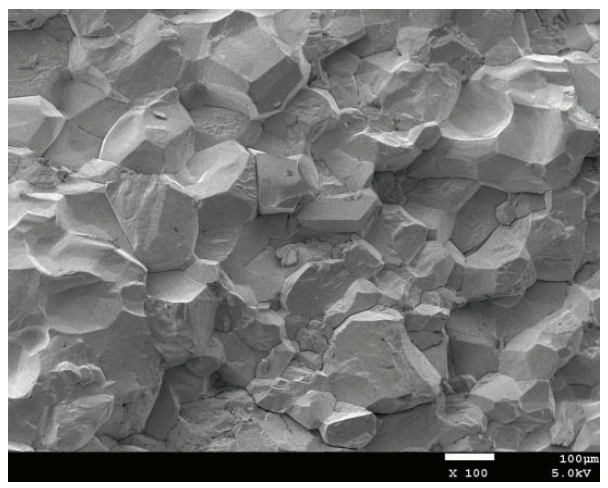

(g) Failure surface of Brazilian splitting test

FIGURE 8: SEM images of fractured surfaces of SCB and Brazilian test specimens with $\times 100$ magnification. 
TABLE 2: Summary of the crack initiation angle $\theta_{0}$ of simulation for different crack inclination angle $\alpha\left(^{\circ}\right)$.

\begin{tabular}{|c|c|c|c|c|c|}
\hline$\alpha$ & $\sigma_{\theta}$-criterion & $S_{\min }$-criterion & $G_{\max }$-criterion & $N T$-criterion & $Y$-criterion \\
\hline 0 & 0 & 0 & 0 & 0 & 0 \\
\hline 10 & 29.1 & 26.0 & 29.8 & 29.3 & 29.0 \\
\hline 20 & 48.8 & 44.7 & 51.6 & 52.8 & 51.1 \\
\hline 30 & 63.7 & 66.5 & 68.5 & 81.3 & 74.8 \\
\hline 34.8 & 70.5 & 80.4 & 75.2 & 98.9 & 88.4 \\
\hline 40 & 70.5 & 80.4 & 75.2 & 98.9 & 88.4 \\
\hline
\end{tabular}

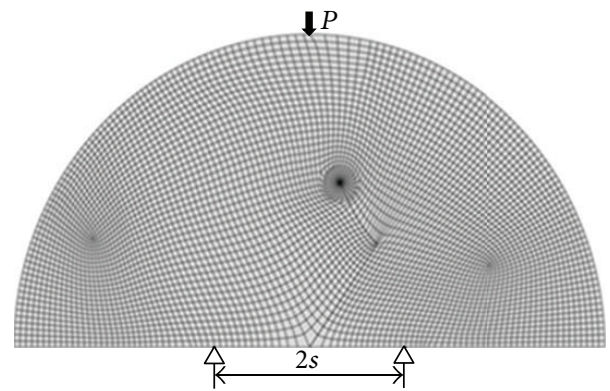

FIGURE 9: Typical finite element mesh used for numerical analysis.

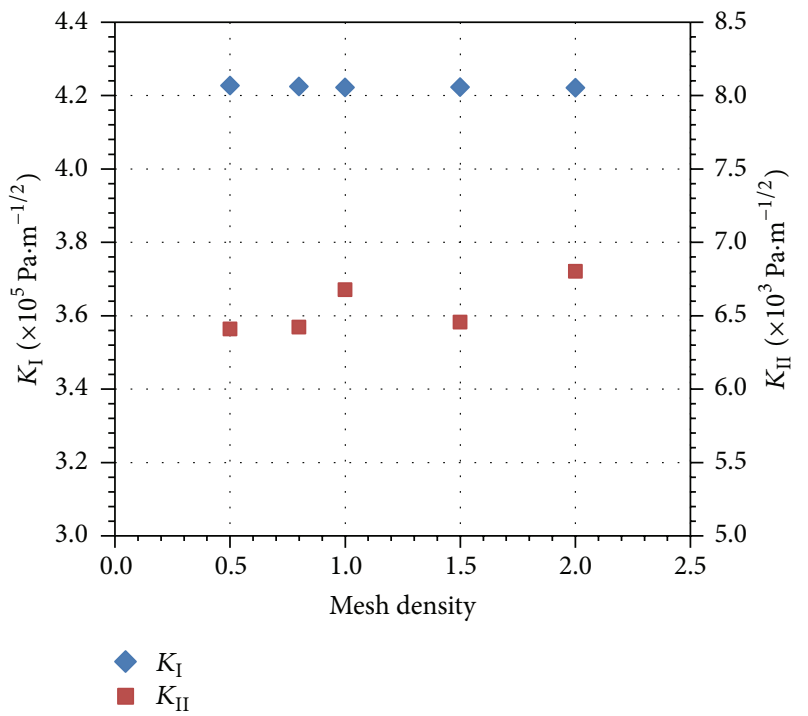

FIGURE 10: Alterations of $K_{\mathrm{I}}$ and $K_{\mathrm{II}}$ with mesh density (the mesh density adopted (Figure 9 in the paper) for numerical simulation in this research is assumed to be 1 ; the mesh density of other numerical models is $0.5,0.75,1.5$, and 2 times as dense as Figure 9).

$Y$-criterion. Hence, when the angle $\alpha$ is small, that is, the proportion of the mode II deformation is relatively small, the difference of the simulated results by the five fracture criteria is negligible. As $\alpha$ increases, the difference in initiation angle between the various fracture criteria becomes apparent. When $\alpha=20^{\circ}$, the difference between different criterions becomes larger. The predicted angle for the $G_{\max }$-criterion is $51.6^{\circ}$ and for the $S_{\min }$-criterion is $44.7^{\circ}$. The difference is about $7^{\circ}$. For $\alpha=30^{\circ}$, the biggest difference between different criterions is nearly $18^{\circ}$. When $\alpha=34.8^{\circ}$, the predicted value changes from 70.5 to $98.9^{\circ}$, a difference of almost $30^{\circ}$. The proportion of the mode II deformation plays an important role in the predicted results of different fracture criteria. When $\alpha=40^{\circ}$, the crack belongs to compression crack. From the perspective of physics, the materials on both sides of the closed crack surface cannot penetrate into each other, and therefore, such cracks are pure model II cracks according to the LEFM. Thus, the initiation angle for the specimen of $\alpha=40^{\circ}$ would be the same as the case of $\alpha=34.8^{\circ}$, as shown in the last two rows of Table 2 . However, this is inconsistent with the experimental results. For $\alpha$ being larger than the angle of pure mode II, the fracture criteria are not applicable.

4.2. Crack Propagation Path. The dolomite specimens' failure paths under various combination loadings of mode I and mode II are plotted in Figure 11. When the sample is subjected to pure mode I, the crack propagates straight along the line of the original crack. As the effect of mode II deformation increases, the crack evolution path becomes curved. When $\alpha=40^{\circ}$, the crack path is the most curving. Figure 12 shows the simulation results of crack trajectories for each inclined angle specimens using the five fracture criteria.

When $\alpha=0^{\circ}$, the crack extension angle is $0^{\circ}$ for each fracture criterion (Figure 12(a)). As $\alpha$ increases from $10^{\circ}$ to $40^{\circ}$, the simulated crack trajectories are very similar for all the fracture criteria. To further examine the crack growth paths calculated by different criteria, the plots of the crack trajectories near the original crack tip are enlarged. At the initial part of crack growth path, the difference between the various fracture criteria is relatively large. This is due to the initial angle of the crack varies between different fracture criteria, but after a few steps of crack growth, the difference between the predicted crack trajectories of the various fracture criteria become smaller and can be neglected. Therefore, any one of the five simulated results can be used for comparison with the experimental results.

After the initial stage of crack propagating, mode I deformation becomes dominant. Taking $\alpha=34.8^{\circ}$ (pure mode II) as an example, after four steps of simulation, the stress intensity factors $K_{\mathrm{I}}$ and $K_{\mathrm{II}}$ calculated by the $S_{\min }$-criterion are 422200 and $6676 \mathrm{~Pa} \cdot \mathrm{m}^{-1 / 2}$, respectively; for the $N T$-criterion, $Y$-criterion, $G_{\max }$-criterion, and $\sigma_{\theta}$-criterion, the values of $K_{\mathrm{I}}$ and $K_{\mathrm{II}}$ are 437400 and $10280 \mathrm{~Pa} \cdot \mathrm{m}^{-1 / 2}, 430400 \mathrm{~Pa} \cdot \mathrm{m}^{-1 / 2}$ and $8607 \mathrm{~Pa} \cdot \mathrm{m}^{-1 / 2}, 427500$ and $3186 \mathrm{~Pa} \cdot \mathrm{m}^{-1 / 2}$, and 429500 and $5892 \mathrm{~Pa} \cdot \mathrm{m}^{-1 / 2}$, respectively. It is obvious that the proportion of mode II deformation is relatively small compared with that of mode I. Based on the discussion in Section 4.1, 


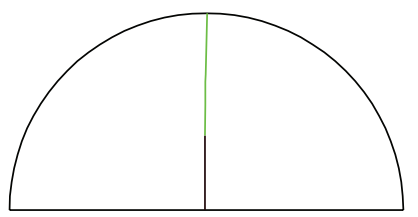

(a) $\alpha=0^{\circ}$

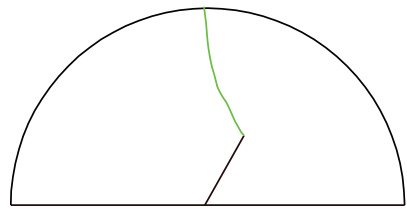

(d) $\alpha=30^{\circ}$

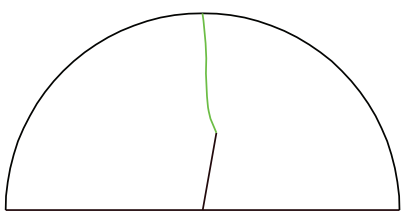

(b) $\alpha=10^{\circ}$

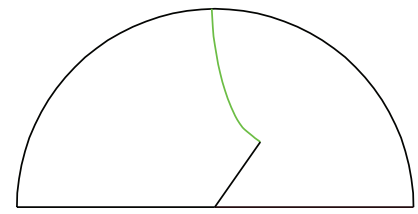

(e) $\alpha=34.8^{\circ}$

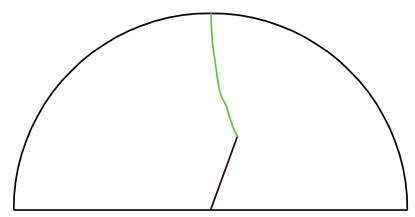

(c) $\alpha=20^{\circ}$

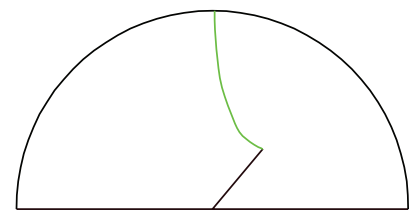

(f) $\alpha=40^{\circ}$

FIGURE 11: Crack path of fractured SCB specimens with different crack inclination angle $\alpha$.

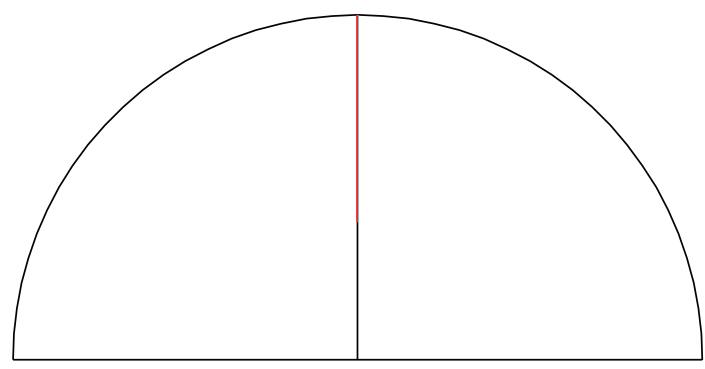

(a) $\alpha=0^{\circ}$

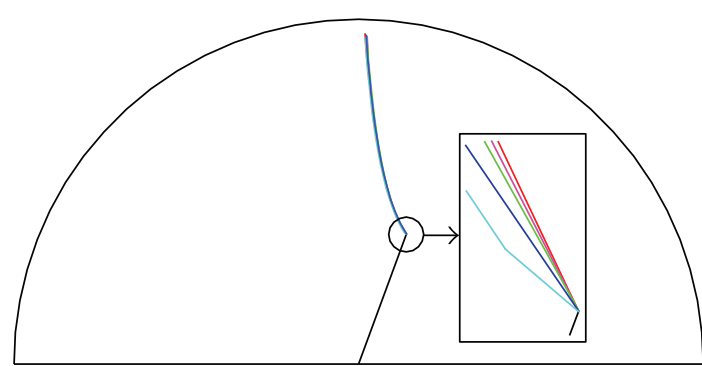

(c) $\alpha=20^{\circ}$

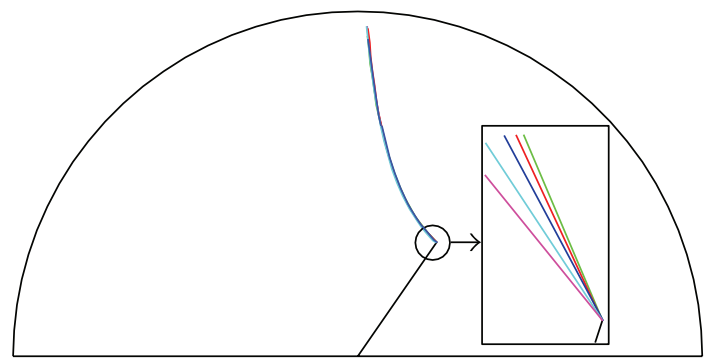

(e) $\alpha=34.8^{\circ}$

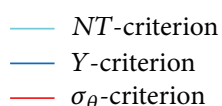

$$
S_{\min } \text {-criterion }
$$$$
\text { - } G_{\max } \text {-criterion }
$$

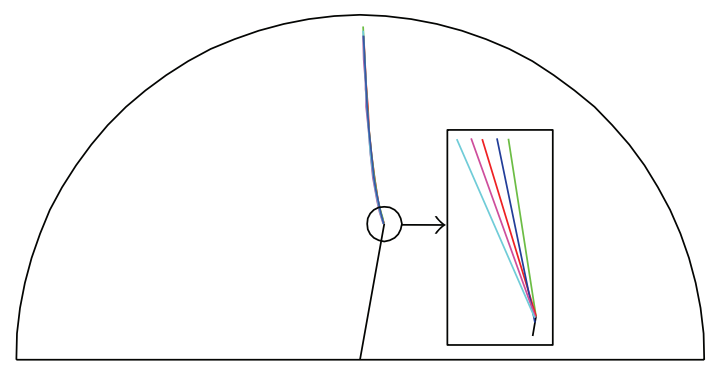

(b) $\alpha=10^{\circ}$

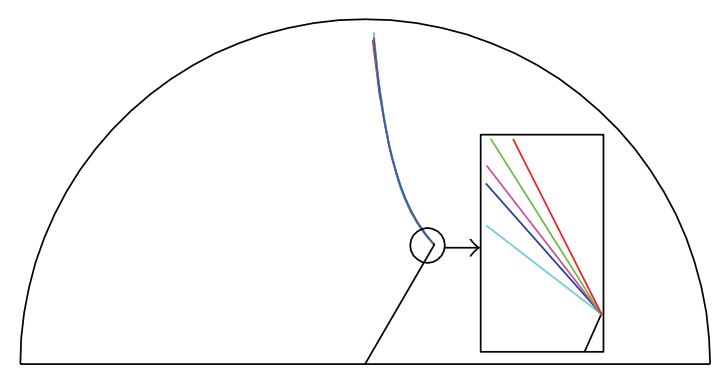

(d) $\alpha=30^{\circ}$

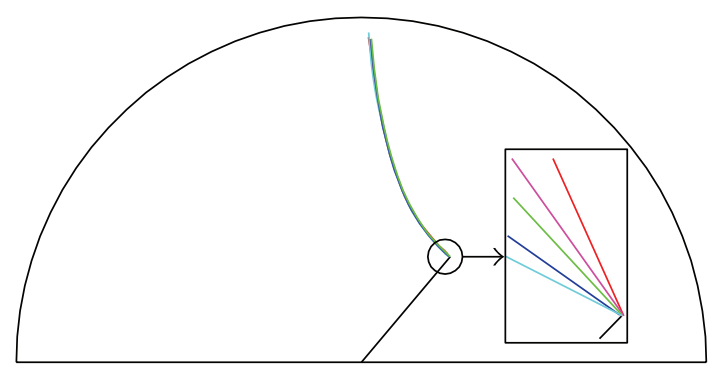

(f) $\alpha=40^{\circ}$

$$
\begin{array}{ll}
N T \text {-criterion } & -S_{\min } \text {-criterion } \\
Y \text {-criterion } & -G_{\max } \text {-criterion }
\end{array}
$$

FIGURE 12: Simulated results of crack trajectories. The red, green, blue, magenta, and cyan lines represent the paths predicted by the $\sigma_{\theta^{-}}$ criterion, $S_{\min }$-criterion, $Y$-criterion, $G_{\max }$-criterion, and $N T$-criterion, respectively. 
TABle 3: Summary of the crack initiation angles $\theta_{0}$ for different Poisson's ratio $\left({ }^{\circ}\right)$.

\begin{tabular}{lccccccccc}
\hline$\alpha$ & \multicolumn{3}{c}{$S_{\min }$-criterion } & \multicolumn{3}{c}{ NT-criterion } & \multicolumn{3}{c}{$Y$-criterion } \\
& $v=0.1$ & $v=0.25$ & $v=0.4$ & $v=0.1$ & $v=0.25$ & $v=0.4$ & $v=0.1$ & $v=0.25$ & $v=0.4$ \\
\hline 0 & 0 & 0 & 0 & 0 & 0 & 0 & 0 & 0 \\
10 & 22.6 & 26.0 & 28.6 & 29.3 & 29.3 & 29.3 & 28.6 & 29.0 & 29.3 \\
20 & 37.4 & 44.7 & 49.6 & 52.8 & 52.8 & 52.8 & 49.4 & 51.1 & 51.9 \\
30 & 59.5 & 66.5 & 72.6 & 81.3 & 81.3 & 81.3 & 72.4 & 74.8 & 76.1 \\
34.8 & 74.5 & 80.4 & 86.2 & 98.9 & 98.9 & 98.9 & 85.9 & 88.4 \\
40 & 74.5 & 80.4 & 86.2 & 98.9 & 98.9 & 98.9 & 85.9 & 88.4 & 89.8 \\
\hline
\end{tabular}

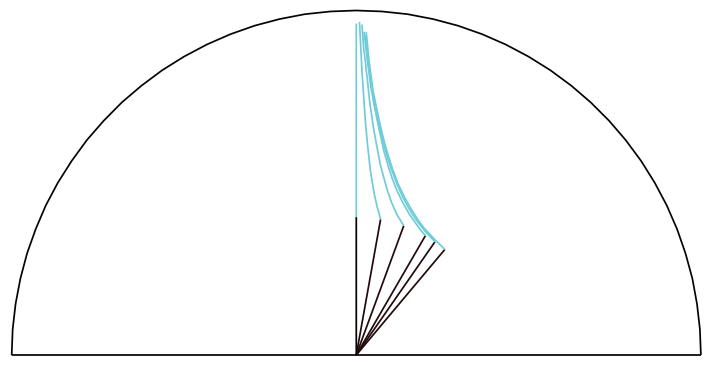

- Crack evolution path

- Original artificial crack

FIGURE 13: Crack trajectories for the different angles of inclination predicted by one fracture criterion (take NT-criterion as an example).

when the proportion of mode I deformation is dominant, the estimated crack initiation angles of all five criteria are similar, which leads to the simulated crack trajectories of the various fracture criteria are similar when the new crack tip moves slightly away from the original crack tip. Examining the predicted crack trajectories for the different angles of inclination using one fracture criterion, and NT-criterion is taken as an example (Figure 13); it is found that when the crack extends to the loading point, the crack paths gradually move close to each other; the same reasons mentioned above can explain this phenomenon.

\subsection{Comparison between the Experimental and Simulated} Results. The crack trajectories predicted based on the five fracture criteria are very similar. Therefore, for simplification, only the simulated crack evolution paths of the $S_{\min }$-criterion were selected to compare with the experimental results. Figure 14 describes the experimental results (crack evolution paths and damaged zones) and the calculated trajectories based on the $S_{\min }$-criterion.

For cracks of pure mode I, the test result coincides with the simulation result of the fracture criteria. When $\alpha=10^{\circ}$, the simulation paths are also in good agreement with the experimental results. For $\alpha=20^{\circ}$, the difference between the experimental result and the simulation result becomes larger but still acceptable. It is interesting that all the predicted crack trajectories of $\alpha=0^{\circ}, 10^{\circ}$, and $20^{\circ}$ are in the damaged zone. That is, the appearance of crack is the consequence of damage evolution and the crack propagation path should locate in the damaged zone. Therefore, when mode I deformation is predominant, the results predicted by the five fracture criteria are reliable. In current work, for predominately mode II cracks $\left(\alpha=30^{\circ}, 34.8^{\circ}\right.$, and $40^{\circ}$ (Figures 14(d)-14(f))), the predicted crack paths locate outside the damaged zones and are not consistent with the experimental results. For a predominately mode II deformation, all the fracture criteria fail to predict the crack path.

4.4. Influence of Poisson's Ratio. Equations (6), (12), and (14) indicate that Poisson's ratio $v$ has an influence on the numerical analysis results. To assess the effect of $v$ quantitatively, three different values ( $v=0.1,0.25$, and 0.4 ) were selected for the numerical analysis. Table 3 summarizes the crack initiation angles $\theta_{0}$ for different Poisson's ratio calculated by the $S_{\text {min }}$-criterion, $N T$-criterion, and $Y$-criterion. The last two rows of Table 3 are the same and the reasons have been explained in Section 4.1. For the NT-criterion, the crack initiation angles do not change with Poisson's ratio, indicating that Poisson's ratio has no effect on the NT-criterion prediction of the crack initiation angle. For the $S_{\min }$-criterion, as Poisson's ratio increases, the predicted crack initiation angle becomes larger. When $\alpha<10^{\circ}$, the difference is relatively small; the maximum difference is less than $7^{\circ}$. For $\alpha>10^{\circ}$, the difference between the results of $v=0.1$ and $v=0.4$ is more than $11^{\circ}$. Poisson's ratio plays an important role in the predicted angle of the $S_{\min }$-criterion. The effect of Poisson's ratio on the $Y$-criterion is similar to that of the $S_{\min }$-criterion, but the effect is much smaller. For $v=0.1$ and $v=0.4$, the biggest difference for the $Y$-criterion is less than $5^{\circ}$. Poisson's ratio has the greatest influence on the $S_{\min }$-criterion, followed by the $Y$-criterion, and no effect on the NT-criterion. Furthermore, the crack trajectories are not sensitive to Poisson's ratio for the three fracture criteria. The simulated results of the crack evolution path are similar to those of Figures 12(a)-12(e).

\section{Conclusions}

Using SCB specimens of dolomite rock, mixed mode brittle fracture was studied by experiments. In order to explain the observed failure behavior, the SEM technique was used to study the microfailure mechanism. Furthermore, by using the conventional remesh method based on FEM, the crack growth trajectories for various mixed mode loading conditions, from pure mode I to mode II, were theoretically 


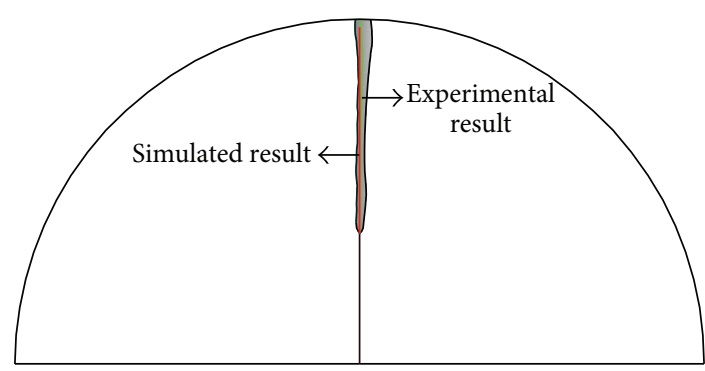

(a) $\alpha=0^{\circ}$

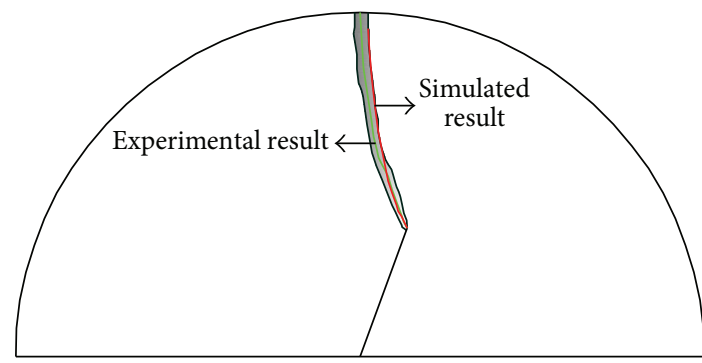

(c) $\alpha=20^{\circ}$

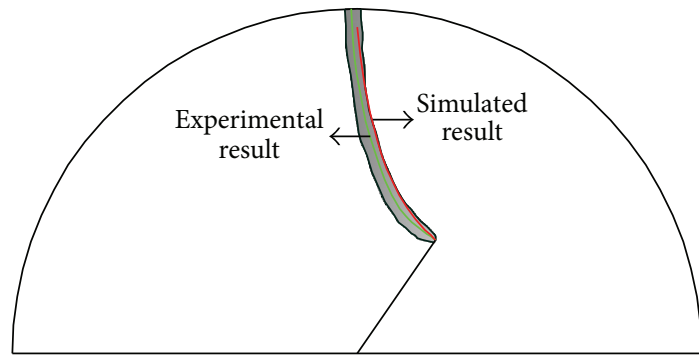

(e) $\alpha=34.8^{\circ}$

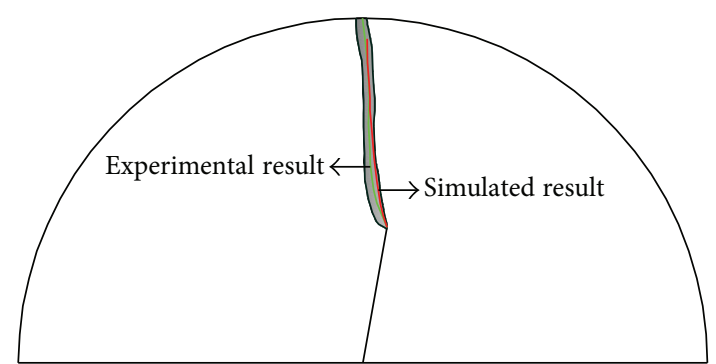

(b) $\alpha=10^{\circ}$

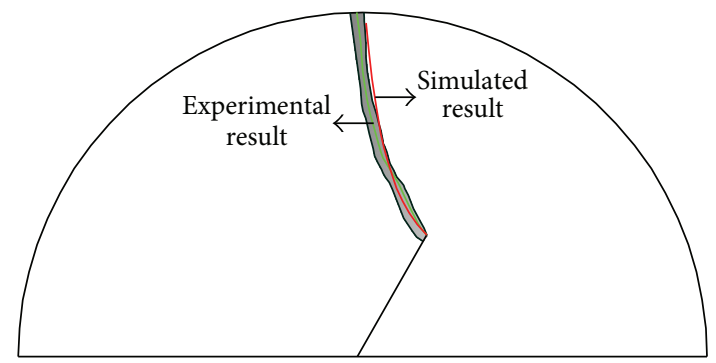

(d) $\alpha=30^{\circ}$

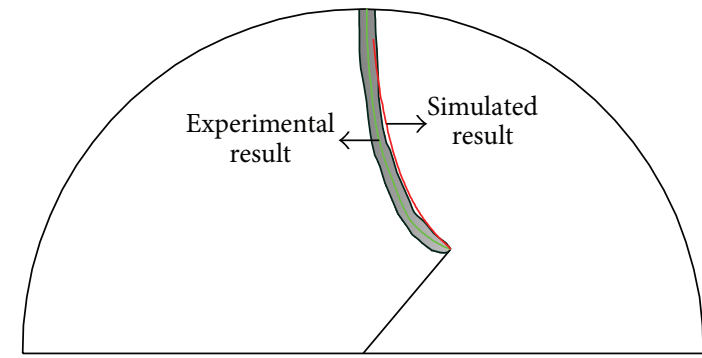

(f) $\alpha=40^{\circ}$

FIGURE 14: Experimental crack propagated paths, damaged zones, and crack trajectories calculated by $S_{\min }$-criterion (the gray zone, red line, and green line represent the damaged zone, numerical result, and experimental result, resp.).

(by the $\sigma_{\theta}$-criterion, $S_{\min }$-criterion, $G_{\max }$-criterion, $N T$ criterion, and $Y$-criterion) and numerically predicted. The applicability of the five criteria was examined. Finally, an investigation on the effect of Poisson's ratio on fracture criteria was also presented. Based on the current work, the following conclusions can be obtained.

(1) The dolomite specimens fracture in a brittle manner: as the proportion of mode II deformation increased, the average failure load increased.

(2) Damaged zones were observed on both sides of the crack. It was a macroscopic experiment that could demonstrate that the emergence of macroscopic cracks was the result of the evolution of damage.

(3) When the crack inclination angle increased, the effect of the shear stress increased but no crushing or abrasion was observed on the cracked surface. When the crack inclined angle was $34.8^{\circ}$ or $40^{\circ}$, evidences of crushing between the cracked faces began to appear.

(4) When mode I deformation was dominant, the difference between the crack initiation angles predicted by the five fracture criteria was small. As the proportion of mode II deformation increased, the difference became larger. Mode II deformation had a considerable impact on the crack initiation angle.

(5) The crack trajectories predicted by the five fracture criteria were very similar and the differences among the prediction paths were negligible.

(6) The predicted crack trajectories were located in the damaged zones for predominately mode I cracks and in such cases, the fracture criteria were suitable; when mode II deformation was predominant, all five fracture criteria failed to predict the crack trajectories.

(7) The crack initiation angle predicted by the $Y$-criterion and $S_{\min }$-criterion was sensitive to Poisson' ratio, particularly the $S_{\min }$-criterion; however, the crack trajectories were not sensitive to Poisson's ratio for these two fracture criteria. For the NT-criterion, the crack initiation angle and the crack trajectories were independent of Poisson's ratio. 


\section{Nomenclature}

\begin{tabular}{|c|c|}
\hline AE: & Acoustic emission \\
\hline$a:$ & Crack length \\
\hline$a / R:$ & Crack length ratio \\
\hline$a_{11}, a_{12}, a_{22}$ & $\begin{array}{l}\text { Parameters defining the stain energy } \\
\text { density factor }\end{array}$ \\
\hline$E$ : & Young's modulus \\
\hline FEM: & Finite element method \\
\hline$G:$ & Energy release rate \\
\hline$G_{\max }$-criterion: & Maximum energy release rate criterion \\
\hline$K:$ & Bulk modulus \\
\hline$K_{\mathrm{I}}:$ & Mode I stress intensity factor \\
\hline$K_{\mathrm{Ic}}:$ & Fracture toughness of pure mode I crack \\
\hline$K_{\mathrm{II}}:$ & Mode II stress intensity factor \\
\hline$K_{\mathrm{III}}:$ & Mode III stress intensity factor \\
\hline$N:$ & Total strain energy density \\
\hline$N_{d}:$ & $\begin{array}{l}\text { Distortional stain energy density in } \\
N T \text {-criterion }\end{array}$ \\
\hline$N_{d, 0}:$ & $\begin{array}{l}\text { A constant distortional stain energy } \\
\text { density in } N T \text {-criterion }\end{array}$ \\
\hline NT-criterion: & $\begin{array}{l}\text { Maximum dilatational strain energy } \\
\text { density criterion }\end{array}$ \\
\hline$N_{v}:$ & $\begin{array}{l}\text { Dilatational stain energy density in } \\
N T \text {-criterion }\end{array}$ \\
\hline$N_{v, \max }:$ & $\begin{array}{l}\text { Maximum dilatational stain energy } \\
\text { density in } N T \text {-criterion }\end{array}$ \\
\hline$P:$ & Applied load \\
\hline$P_{c r}:$ & Failure load \\
\hline$R:$ & Radius of SCB specimens \\
\hline$r \theta:$ & Crack tip coordinates \\
\hline$r_{o}:$ & A constant radius \\
\hline$r_{p}:$ & Elastic-plastic boundary \\
\hline$r_{p c r}$ & Critical radius in $N T$-criterion \\
\hline$S:$ & Stain energy density factor \\
\hline$S_{\min }$-criterion: & Minimum stain energy density criterion \\
\hline SCB: & Semicircular bend \\
\hline SEM: & Scanning electron microscope \\
\hline $2 s:$ & Loading span in the SCB test \\
\hline$s / R:$ & $\begin{array}{l}\text { Loading point span ratio in SCB } \\
\text { specimen }\end{array}$ \\
\hline$t:$ & Thickness of specimens \\
\hline$Y$-criterion: & $\begin{array}{l}\text { Distortional strain energy density } \\
\text { criterion }\end{array}$ \\
\hline$Y_{d}:$ & $\begin{array}{l}\text { Distortional stain energy density in } \\
Y \text {-criterion }\end{array}$ \\
\hline$Y_{d, 0}:$ & $\begin{array}{l}\text { Critical value distortional stain energy } \\
\text { density }\end{array}$ \\
\hline$Y_{d, \theta 0}:$ & $\begin{array}{l}\text { Minimum of distortional stain energy } \\
\text { density }\end{array}$ \\
\hline$Y_{v}:$ & $\begin{array}{l}\text { Dilatational stain energy density in } \\
Y \text {-criterion }\end{array}$ \\
\hline XRD: & $\mathrm{X}$-ray diffraction \\
\hline$\mu:$ & Shear modulus \\
\hline$\sigma_{r r}, \sigma_{\theta \theta}, \sigma_{r \theta}$ & $\begin{array}{l}\text { Stress components near the crack tip in } \\
\text { polar coordinates }\end{array}$ \\
\hline$\sigma_{x x}, \sigma_{y y}, \sigma_{x y}$ & $\begin{array}{l}\text { Stress components near the crack tip in } \\
\text { Cartesian coordinates }\end{array}$ \\
\hline & Critical material yield strength \\
\hline
\end{tabular}

$\sigma_{\theta}$-criterion: Maximum tangential stress criterion

$\begin{array}{ll}\alpha: & \text { Crack inclination angle } \\ \theta_{0}: & \text { Crack initiation angle. }\end{array}$

\section{Acknowledgments}

This work was financially supported by the Provincial Science and Technology Support Project (2012FZ0124), Major State Basic Research Project (2011CB201201), and the International Science \& Technology Cooperation Program of China (2012DFA60760).

\section{References}

[1] S.-H. Chang, C.-I. Lee, and S. Jeon, "Measurement of rock fracture toughness under modes I and II and mixed-mode conditions by using disc-type specimens," Engineering Geology, vol. 66, no. 1-2, pp. 79-97, 2002.

[2] I. L. Lim, I. W. Johnston, S. K. Choi, and J. N. Boland, "Fracture testing of a soft rock with semi-circular specimens under threepoint bending. Part 2-mixed-mode," International Journal of Rock Mechanics and Mining Sciences and, vol. 31, no. 3, pp. 199212, 1994

[3] Z. Jia, A. Castro-Montero, and S. P. Shah, "Observation of mixed mode fracture with center notched disk specimens," Cement and Concrete Research, vol. 26, no. 1, pp. 125-137, 1996.

[4] G. S. Xeidakis, I. S. Samaras, D. A. Zacharopoulos, and G. E. Papakaliatakis, "Trajectories of unstably growing cracks in mixed mode I-II loading of marble beams," Rock Mechanics and Rock Engineering, vol. 30, no. 1, pp. 19-33, 1997.

[5] A. Bobet and H. H. Einstein, "Fracture coalescence in rocktype materials under uniaxial and biaxial compression," International Journal of Rock Mechanics and Mining Sciences, vol. 35, no. 7, pp. 863-888, 1998.

[6] C.-S. Chen, E. Pan, and B. Amadei, "Fracture mechanics analysis of cracked discs of anisotropic rock using the boundary element method," International Journal of Rock Mechanics and Mining Sciences, vol. 35, no. 2, pp. 195-218, 1998.

[7] B. Vásárhelyi and A. Bobet, "Modeling of crack initiation, propagation and coalescence in uniaxial compression," Rock Mechanics and Rock Engineering, vol. 33, no. 2, pp. 119-139, 2000.

[8] R. H. C. Wong, C. A. Tang, K. T. Chau, and P. Lin, "Splitting failure in brittle rocks containing pre-existing flaws under uniaxial compression," Engineering Fracture Mechanics, vol. 69, no. 17, pp. 1853-1871, 2002.

[9] N. A. Al-Shayea, "Crack propagation trajectories for rocks under mixed mode I-II fracture," Engineering Geology, vol. 81, no. 1, pp. 84-97, 2005.

[10] H. Y. Liu, S. Q. Kou, P.-A. Lindqvist, and C. A. Tang, "Numerical modelling of the heterogeneous rock fracture process using various test techniques," Rock Mechanics and Rock Engineering, vol. 40, no. 2, pp. 107-144, 2007.

[11] M. R. M. Aliha, M. R. Ayatollah, D. J. Smith, and M. J. Pavier, "Geometry and size effects on fracture trajectory in a limestone rock under mixed mode loading," Engineering Fracture Mechanics, vol. 77, no. 11, pp. 2200-2212, 2010.

[12] F. Erdogan and G. C. Sih, "On the crack extension in plates under plane loading and transverse shear," Journal of Basic Engineering, vol. 85, no. 4, pp. 519-527, 1963. 
[13] G. C. Sih, "Strain-energy-density factor applied to mixed mode crack problems," International Journal of Fracture, vol. 10, no. 3, pp. 305-321, 1974.

[14] K. Palaniswamy and W. G. Knauss, "Propagation of a crack under general, in-plane tension," International Journal of Fracture Mechanics, vol. 8, no. 1, pp. 114-117, 1972.

[15] M. A. Hussain, S. L. Pu, and J. Underwood, "Strain energy release rate for a crack under combined Mode I and Mode II," Fracture Analysis STP 560, ASTM, 1974.

[16] R. J. Nuismer, "An energy release rate criterion for mixed mode fracture," International Journal of Fracture, vol. 11, no. 2, pp. 245250, 1975.

[17] C. H. Wu, "Fracture under combined loads by maximumenergy-release-rate criterion," Journal of Applied MechanicsTransactions ASME, vol. 45, no. 3, pp. 553-558, 1978.

[18] A. P. Kfouri and M. W. Brown, "Fracture criterion for cracks under mixed-mode loading," Fatigue \& Fracture of Engineering Materials and Structures, vol. 18, no. 9, pp. 959-969, 1995.

[19] N. A. B. Yehia and M. S. Shephard, "The nt-criterion for predicting crack growth increments," Engineering Fracture Mechanics, vol. 26, no. 3, pp. 371-382, 1987.

[20] N. A. B. Yehia, "Distortional strain energy density criterion: the $Y$-Criterion," Engineering Fracture Mechanics, vol. 39, no. 3, pp. 477-485, 1991.

[21] K. P. Chong and M. D. Kuruppu, "New specimen for fracture toughness determination for rock and other materials," International Journal of Fracture, vol. 26, no. 2, pp. R59-R62, 1984.

[22] M. R. Ayatollahi and M. R. M. Aliha, "Wide range data for crack tip parameters in two disc-type specimens under mixed mode loading," Computational Materials Science, vol. 38, no. 4, pp. 660-670, 2007.

[23] G. M. Fonseka, S. A. F. Murrell, and P. Barnes, "Scanning electron microscope and acoustic emission studies of crack development in rocks," International Journal of Rock Mechanics and Mining Sciences and Geomechanics Abstracts, vol. 22, no. 5, pp. 273-289, 1985. 


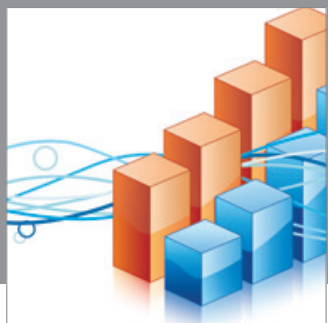

Advances in

Operations Research

mansans

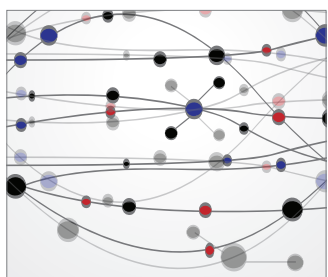

The Scientific World Journal
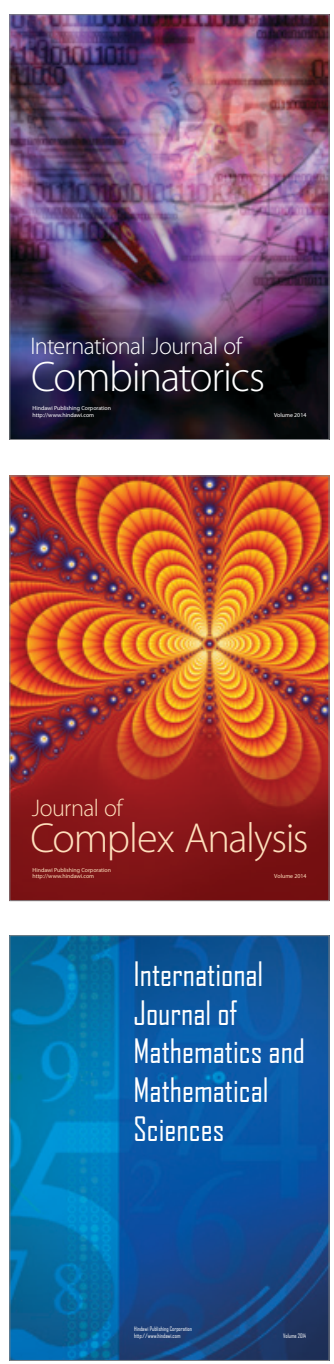
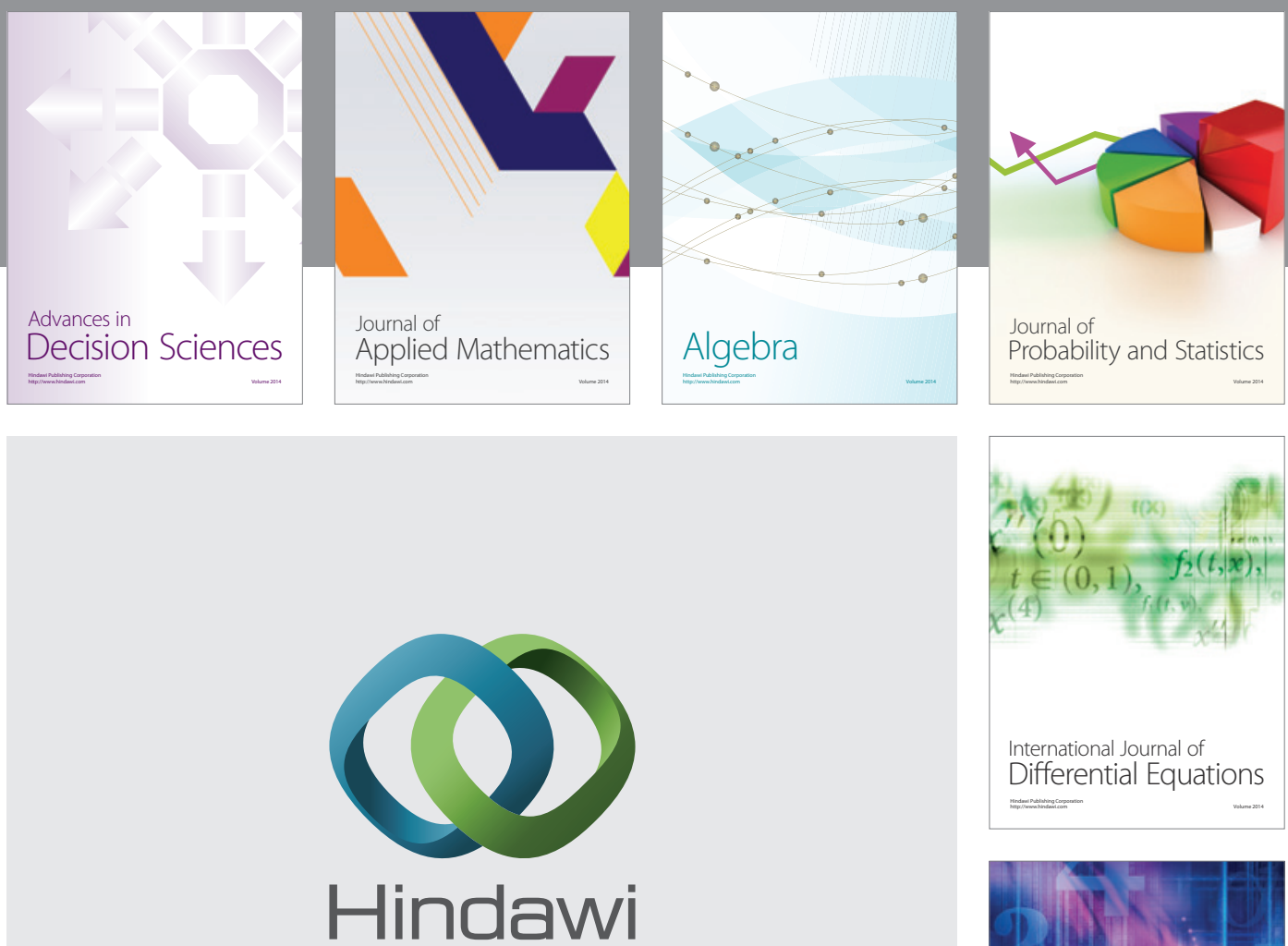

Submit your manuscripts at http://www.hindawi.com
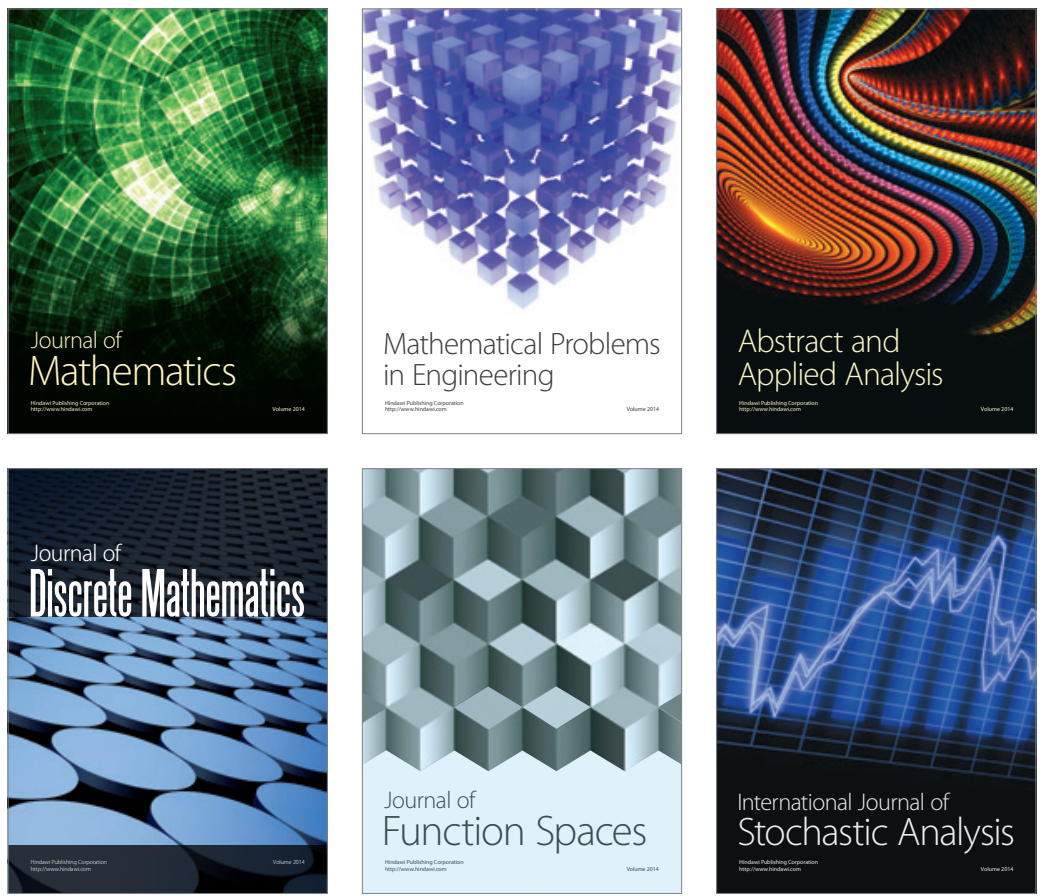

Journal of

Function Spaces

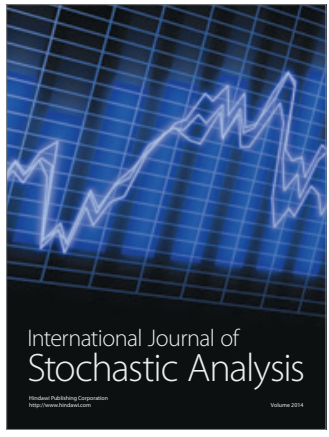

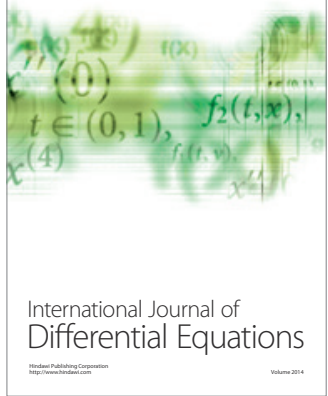
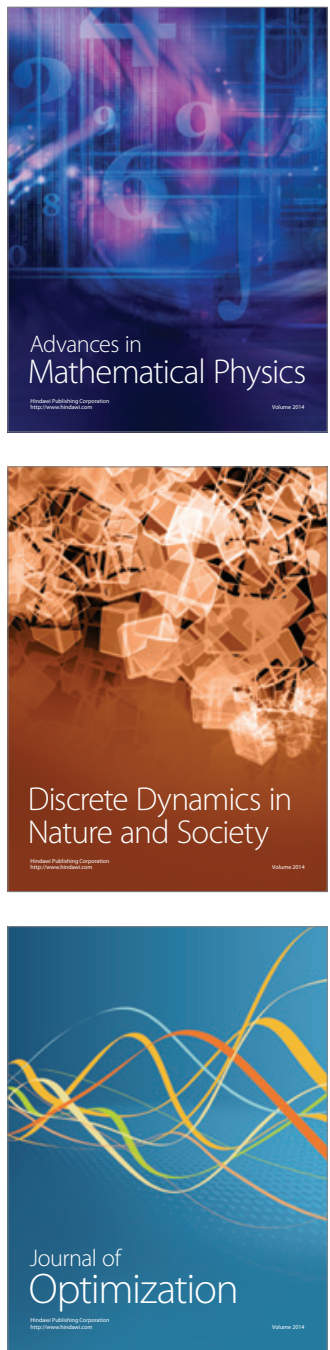